\title{
13
}

\section{Integration of SWMM into a Dam Break, Hurricane, and Extreme Flood Modeling and Damage Assessment Framework}

David R. Judi, Alfred J. Kalyanapu, Timothy McPherson and Steven J. Burian

SWMM5 has been seamlessly integrated with a Geographic Information System (GIS) for simulation of inundation and analysis of consequences resulting from extreme flood events. The GIS-based environment processes digital elevation models, land use/cover data, stream networks and soils to create stream network, sub-basins, and cross-section shapefiles for river basins selected for analysis. The following readily-available public-domain datasets are utilized:

- 30-m topographical data from the United States Geological Survey (USGS),

- 30-m NLCD,

- Natural Resources Conservation Service (NRCS) (STATSGO), and

- National Hydrography Dataset (NHD).

Rainfall predictions are made by a numerical weather model and ingested in gridded format into the simulation environment. Runoff hydrographs are estimated using Green-Ampt infiltration excess runoff prediction and a onedimensional diffusive wave overland flow routing approach. The hydrographs and the channel morphology are used to generate a SWMM5 compatible

Judi, D., A.J. Kalyanapu, T. McPherson and S. Burian. 2009. "Integration of SWMM into a Dam Break, Hurricane, and Extreme Flood Modeling and Damage Assessment Framework." Journal of Water Management Modeling R235-13. doi: 10.14796/JWMM.R235-13.

C CHI 2009 www.chijournal.org ISSN: 2292-6062 (Formerly in Conceptual Modeling of Urban Water Systems. ISBN: 978-0-9808853-2-3) 
input file. The input file is seamlessly passed to SWMM5 using a Dynamic Link Library (DLL) to model the flood wave propagation using the dynamic wave model. The resulting hydraulic grade lines are subsequently passed back into the GIS framework for transformation into inundation maps to be used in damage assessment. This model has been applied to modeling of dam breaks, hurricanes, and extreme flooding events in the United States. Results from dam break simulations are presented in this chapter along with a discussion on the performance of SWMM5 for this application.

\subsection{Introduction}

Annually, large scale flood events cause extensive damage to communities and their supporting infrastructure in the United States. In order to adequately analyze the risk to communities and infrastructure, flooding and damage assessment must be estimated over wide areas (thousands of square miles) and must be completed quickly (hours to days). Computer models have been applied since 1966 to simulate flood impacts (Crawford and Linsley, 1966). Since the first applications, numerous computer models have been developed to assist modelers in flood mitigation planning and flood control design (Singh and Woolhiser, 2002). Existing models do not provide the capability to simulate runoff from wide areas, estimate inundation extent and magnitude, determine damages to infrastructure systems, and assess consequences of infrastructure interdependencies in a seamless process. Given the need to rapidly produce information necessary to mitigate impacts from critical infrastructure failures, a computationally efficient modeling framework was necessary. Developing an entirely new modeling framework was unnecessary because the benefits of years of model development can be easily accessed in open source codes and integrated with new codes to create a fast-response flood modeling framework for wide area applications.

In developing a flood inundation and damage assessment modeling framework, several constraints must be considered. These constraints include the scale of the event, the resolution required of the study, and model building time. Events of National Importance (hurricane, tropical storm, dam break, etc...) may have an effect on multiple states and thousands of miles of rivers. While the tendency may be to complete a lower resolution study to cover the larger area, the study must be completed at the necessary resolution to assess the impacts at the asset level. Finally, the time required to build models for large scale analysis using existing modeling and simulation capability can take 
weeks to months to complete which makes it difficult to utilize simulation results in emergency response decision making.

Given these requirements, a modeling simulation capability has been developed blending existing software and new computer code within a geographic information system (GIS) environment. The Infrastructure Consequence Flood Inundation Tool (ICFIT) rapidly simulates flooding from extreme events and develops inundation contours to be used in the assessment of damage to and impacts on the operation of infrastructure systems. This chapter describes the framework, highlights the use of SWMM5, presents a case study application for dam break flood inundation modeling, and considers the performance of SWMM5.

\subsection{Model Framework}

A simulation framework has been developed which provides the capability to rapidly simulate flooding from extreme events (Judi et al. 2007) The framework operates within a GIS to take advantage of built-in spatial processing and analysis functionality. To facilitate rapid application, the framework uses readily available datasets as inputs, eliminating the need for data collection efforts that are not possible given the time frame of application (days) and in addition would be cost prohibitive. The simulation framework comprises four flood simulation modules: (i) input, (ii) hydrologic simulation, (iii) hydraulic simulation, and (iv) inundation (the modules to simulate damages and analyze infrastructure impacts are not relevant to this chapter and are not described herein). The four modules are linked by seamless data bridges in the GIS interface and results are delivered in formats compatible with subsequent damage assessment, infrastructure simulation, and visualization tools. Details of the four modules are provided below.

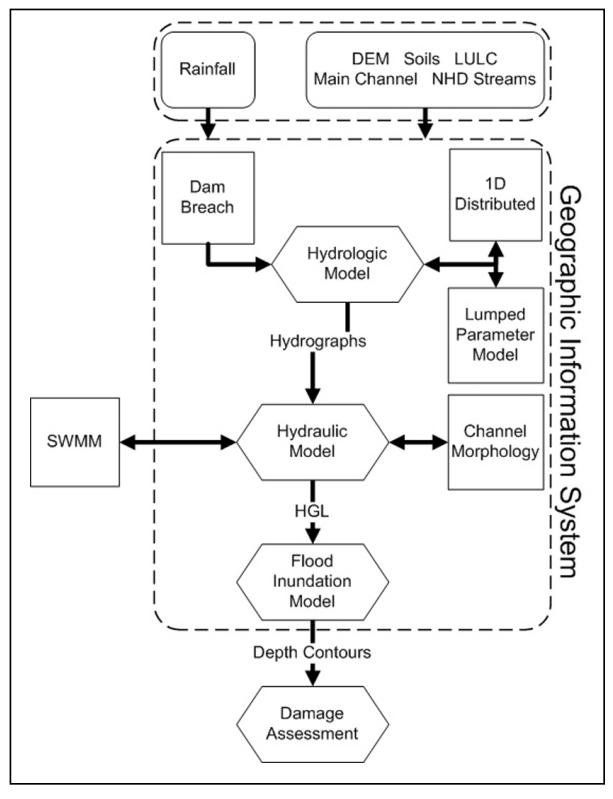

Figure 13.1 Model simulation framework. 


\subsubsection{Model Input Datasets}

The simulation framework utilizes datasets that are readily available for download. The datasets include digital elevation model (DEM) data (30-m from the USGS (www.seamless.usgs.gov)), land use/cover (LULC) data (30-m NLCD (www.seamless.usgs.gov)), stream networks from the National Hydrography Dataset (NHD (http://nhd.usgs.gov)) and soils data from the NRCS (STATSGO (http://soildatamart.nrcs.usda.gov/)). Additionally, gridded rainfall data for rain-driven flood events generated by a numerical weather model (e.g. Mesoscale Model 5 (MM5)) may be used in the hydrologic model. These datasets are ingested into the necessary models during the simulation.

\subsubsection{Hydrologic Model}

The objective of the hydrologic model is to develop runoff hydrographs for each sub-basin. Required inputs into this model include the DEM, rainfall data, soil, and LULC data for parameter estimation (e.g. infiltration, roughness). The sub-basin runoff estimation is completed using one of two computation modules, a one-dimensional distributed hydrologic model (DHM) or a lumped parameter model (SWMM5).

The DHM is a physically-based approach to determine surface runoff. The Green-Ampt infiltration model is used to estimate excess rainfall, which is subsequently routed using a one-dimensional diffusive wave method. DHM simulates on a raster basis where the watershed is divided into equalsized grid cells and each grid cell serves as a hydrologic element in the simulation. The grid cells are linked by flow direction based on surface topography.

Because the DHM is a raster-based model, the processing can be computationally intensive. To provide an alternative to use in situations requiring greater efficiency, lumped parameter modeling approaches have been incorporated into the modeling framework. The framework includes the ability to use either Snyder's unit hydrograph, which is based on geometric properties of the sub-basin, or the U.S. EPA's Storm Water Management Model, Version 5 (SWMM5).

As an alternative to rainfall driven hydrograph development, the simulation framework also is capable of estimating hydrographs generated by other extreme events, most notably dam break events. Using the approach implemented in the National Weather Service DAMBREAK model (Fread, 
1991), ICFIT develops dam break hydrographs and passes them to the channel hydraulic model and eventually inundation mapping.

\subsubsection{Hydraulic Model}

The hydrographs generated in the hydrologic or dam break models are passed into the hydraulic model for flood wave routing. Additional data requirements to accomplish this task include the DEM and the channel hydrography. Because SWMM5 is easily accessed through a DLL and can be run from within a GIS, hydraulic routing is completed using the dynamic wave simulation capability of SWMM5. SWMM5 does not reside within the GIS, but is accessed by the model's DLL. Prior to routing the flood wave, however, a SWMM5 compatible input file must be generated in order to run a successful simulation. The SWMM5 input file consists of several keywords, or headers, which contain information describing the network configuration and simulation settings. For the purpose of this chapter, the keywords are categorized into channel morphology inputs, junction inflow inputs, and simulation option inputs.

\section{Channel Morphology Inputs}

The most fundamental dataset for one-dimensional hydraulic routing of flood flows is a channel morphology dataset. For SWMM5, the channel morphology must include a connected system of junctions and conduits. For open channel simulations, the conduits must contain channel cross sectional information. This input is generated in the hydraulic model using only a line feature describing the flow path and a DEM, as shown in Figure 13.2 below.

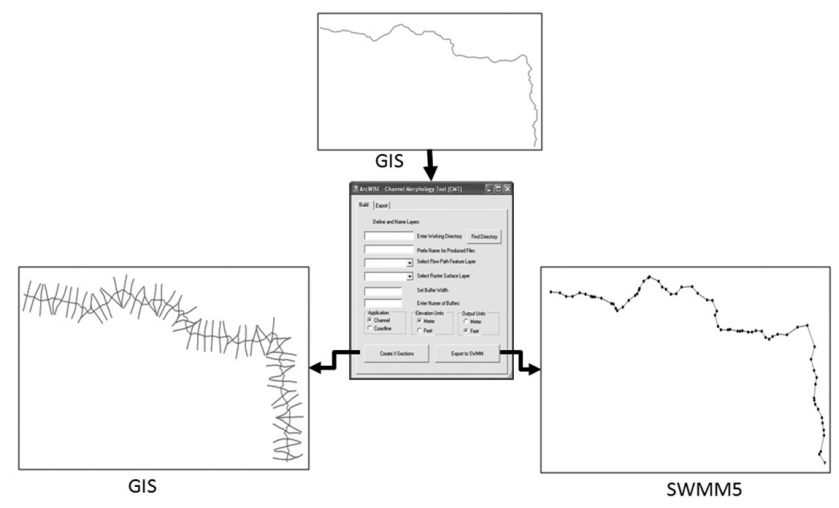

Figure 13.2 SWMM5 channel morphology development process. 
Junctions are placed at a user specified distance along the provided channel, thus the conduit becomes the channel between junctions. The cross section lines are created at midpoints between junctions, and stationelevation pairs are extracted along the line from the DEM in an automated process (Kalyanapu et al., 2007). The GIS generated channel morphology is then written into the appropriate SWMM5 input file sections.

\section{Junction Inflow Inputs}

SWMM5 allows external inflows to enter the system at junction locations. Therefore, the hydrographs which were generated from the hydrologic model must be assigned to a junction developed as part of the channel morphology inputs. The assignment is made by locating the closest junction to the outlet of the sub-basin and associating the corresponding hydrograph and junction ID (Figure 13.3). For dam break simulation, the hydrograph is assigned to the most upstream located junction.

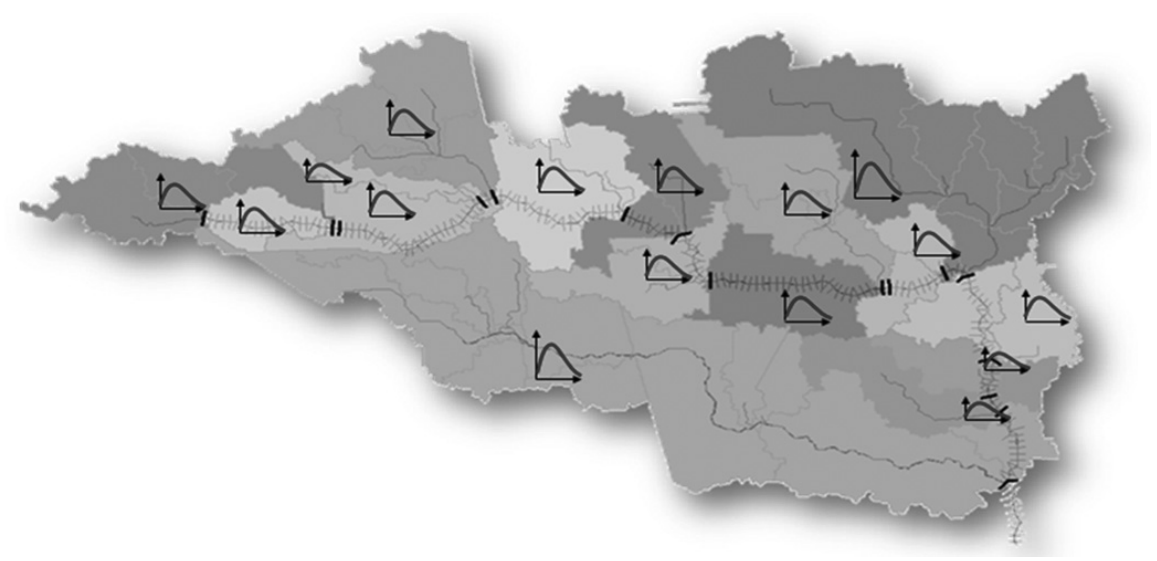

Figure 13.3 Hydrograph assignment as SWMM5 junction inflow.

\section{Simulation Option Inputs}

The simulation option inputs control how the simulation of the system is carried out. This includes the routing method, the dates of simulation, computational time step parameters, and parameters that control how the dynamic wave flow routing computations are made (Rossman 2008). Additionally, the information desired to be included in the output report file should be specified in this section. 
Upon completion, the input file is passed into the SWMM5 engine through a DLL and the simulation is executed. When the simulation has completed, a report file is generated and imported into the framework. From the report file, the maximum hydraulic grade line (HGL) from each junction (Figure 13.4) is extracted and passed into the flood inundation model.

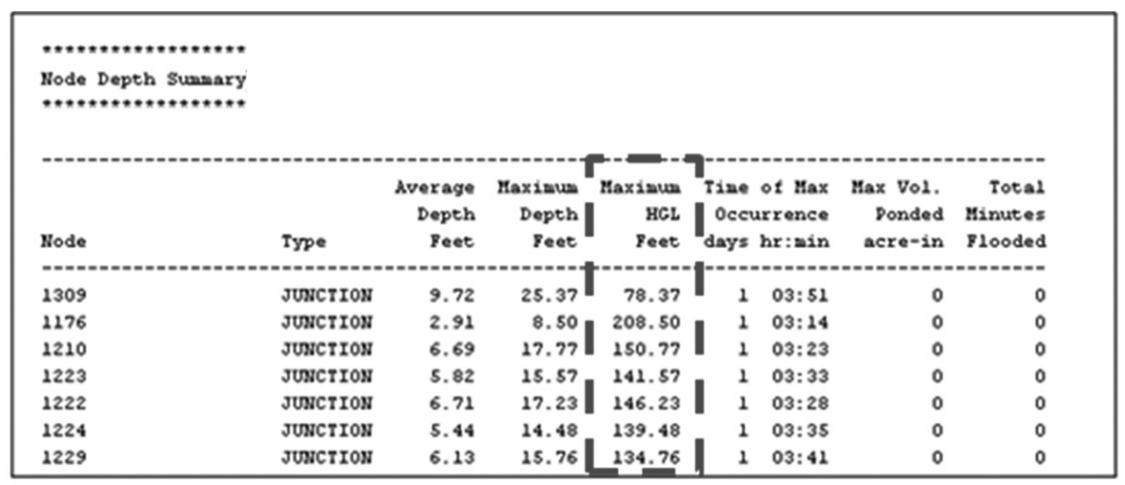

Figure 13.4 HGL extraction from SWMM5 status report.

\subsubsection{Flood Inundation Model}

The HGL values, along with the DEM, the channel morphology (GIS data), and channel hydrography are used to determine the flooded areas. The ultimate goal of the flood inundation model is to develop a flood depth contour shapefile to be used as a damage and infrastructure assessment tool. The process of creating the map is described in three steps: (i) flood boundary delineation, (ii) creation of a water surface grid, and (iii) computation of the flood depth contours.

A flood boundary polygon is necessary to limit the flood analysis extent in a 'planar' mapping approach such as this. This helps to reduce areas of flooding that are not hydraulically connected to the actual flood. These areas may be lower lying areas that are protected by high ground/berms (e.g. highway underpasses). The boundary polygon is created by simply comparing HGL and DEM values starting at the river flow line and moving outwards until the boundary is reached for each cross section.

The water surface grid is a two-dimensional representation of the onedimensional HGL generated from the dynamic wave simulation. This grid is 
created by interpolating the HGL values obtained at each junction using available GIS tools.

The final step is to calculate the flood depth contours. This is done by first subtracting the DEM from the water surface grid, followed by the elimination of all flooding outside the flood boundary polygon. The resulting depth contours are passed into the damage estimation model.

\subsection{Case Study}

The simulation framework described in this chapter is used to simulate the flood wave and resulting inundation from a hypothetical dam located in the United States. The objective of the simulation is to demonstrate the capability of SWMM5 used as a flood estimation model for extreme events (e.g. dam break, hurricane, etc...) using dynamic wave routing.

\subsubsection{Dam Break Description}

The hypothetical dam has a capacity of $2.5 \mathrm{M}$ acre- $\mathrm{ft}$ ( 3.08 billion $\mathrm{m}^{3}$ ), with a maximum depth of approximately $300 \mathrm{ft}(90 \mathrm{~m})$. The hydrographs for the dam break simulation are developed using the dam break module described previously. For this study, a series of 5 hydrographs were developed for varying initial water surface elevations in the reservoir. Inundation resulting from varying water surface levels is of interest since the level in most reservoirs varies greatly throughout the water year. Table 13.1 below provides a description of the temporal and geometric parameters used in describing each of the break scenarios, and Figure 13.5 shows the resulting hydrographs with peaks ranging from $1.6 \mathrm{M}$ to $0.89 \mathrm{M} \mathrm{cfs}(45,300$ to $25,200 \mathrm{cms}$ ). A sample map of inundation resulting from the dam break is shown in Figure 13.6.

Table 13.1 Temporal and geometric breach parameters.

\begin{tabular}{ccccccc}
\hline & $\begin{array}{c}\text { Initial } \\
\text { Water } \\
\text { Revel } \\
(\mathrm{ft})\end{array}$ & $\begin{array}{c}\text { Breach } \\
\text { Terminal } \\
\text { Depth } \\
(\mathrm{ft})\end{array}$ & $\begin{array}{c}\text { Time to } \\
\text { Complete } \\
\text { Failure (hr) }\end{array}$ & $\begin{array}{c}\text { Breach } \\
\text { Terminal } \\
\text { Width } \\
(\mathrm{ft})\end{array}$ & $\begin{array}{c}\text { Width at } \\
\text { Breach } \\
\text { Bottom }\end{array}$ & $\begin{array}{c}\text { Breach } \\
\text { Side } \\
\text { Slope }\end{array}$ \\
\hline 1 & 300 & 0 & 1.43 & 81 & 3000 & 1.04 \\
2 & 275 & 0 & 1.43 & 81 & 3000 & 1.04 \\
3 & 250 & 0 & 1.43 & 81 & 3000 & 1.04 \\
4 & 225 & 0 & 1.43 & 81 & 3000 & 1.04 \\
5 & 200 & 0 & 1.43 & 81 & 3000 & 1.04 \\
\hline
\end{tabular}




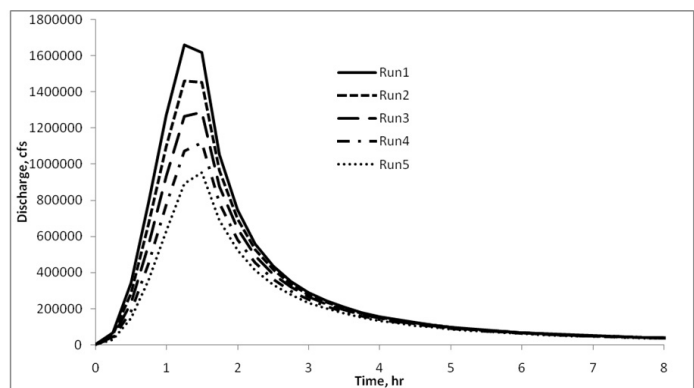

Figure 13.5 Dam breach hydrographs for varying water surface elevations.

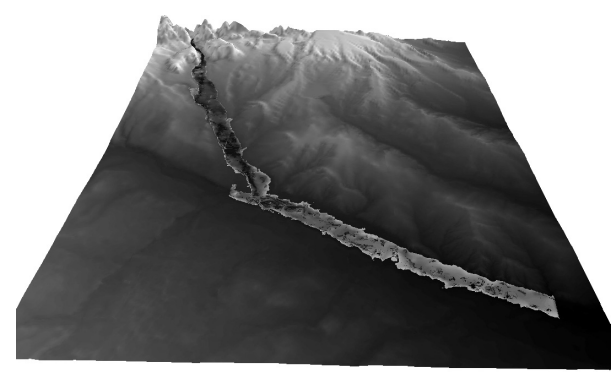

Figure 13.6 Dam breach inundation map.

\subsubsection{Analysis of SWMM5 Performance for Dam Break}

As an indication of computational performance, SWMM5 reports mass continuity error for flow routing, which is a representation of the percent difference between initial storage + total inflows and final storage + total outflow for the entire system (Rossman 2008). The SWMM5 manual recommends that if the continuity error exceeds some reasonable level $(\sim 10 \%)$, then the validity of the analysis should be questioned. One factor in dynamic wave routing that will have an effect on the computational accuracy is the computational time step, which can either be too long or too short. To determine the effect of time step on continuity error for dam break flows, each of the hydrographs were simulated twice - one simulation using a default routing time step of $30 \mathrm{~s}$, and then reducing the time step to one second for a higher temporal resolution. The mass continuity error for flow routing from each of the simulations is shown in Figure 13.7. 


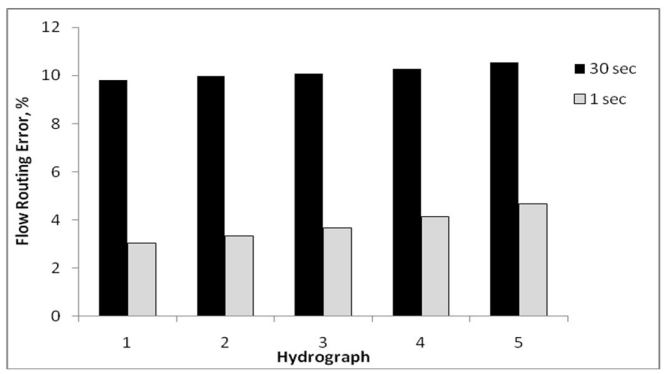

Figure 13.7 Mass continuity error for dam break simulations with varying time step.

It is first noted that the resulting errors in the simulations are all positive, indicating that the model is numerically diffusive and "losing" some water during the simulation (a negative error would indicate the opposite). The results show that the smaller time step greatly reduces the continuity error in the simulation. For a time step of $30 \mathrm{~s}$, the error in all simulations was around $10 \%$, while for the $1 \mathrm{~s}$ time step the error ranged from 3-4\%. Since the objective of the simulation framework is to develop flood contours for damage assessment, it is important to know the relationship between change in error and change in flood inundation area. To check this, the total area of flooding resulting from each of the simulations was calculated and shown in Figure 13.8.

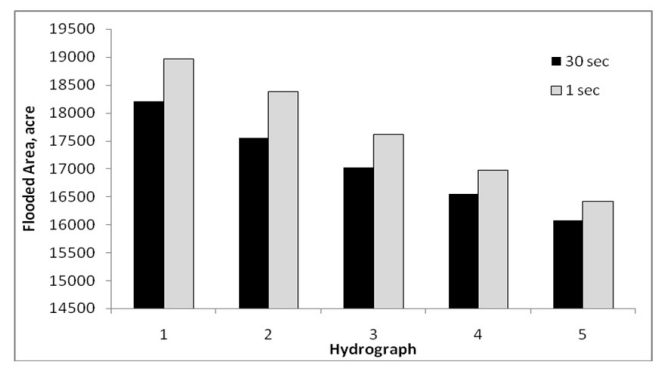

Figure 13.8 Total flooded area for dam break simulation runs with varying time step.

The results indicate that for less continuity error (smaller time step), the flooded area increases compared to the flooded area associated with the larger time step (also verifies that the reduced error is less numerically diffusive thus "loses" less water). However, given that the routing error was decreased by as much as $70 \%$, the change in flooded area was only about a 
4\% decrease. Although this difference is relatively insignificant, consideration should be given to accuracy versus computation time, since a smaller time step is more computationally intensive. It is also noted that the effect that the computational error has on the flood inundation area may also include site-specific topographic considerations.

This set of simulations focused on SWMM5's ability to simulate large flows. From the results, it appears that the model has the ability to route the flood wave and while remaining stable. It is also shown that the continuity error can be minimized in the simulation by reducing the computational time step. However, the study has not provided any indication on the models ability to conserve momentum, which is an important consideration in the modeling of extreme flood waves. Since the SWMM5 engine does not provide capability to check this from the interface, this will be the subject of future studies.

\subsection{Conclusions}

A simulation framework for modeling of extreme flood events (e.g. hurricane, tropical storm, dam break) has been described in this chapter. The GIS-based environment processes readily-available digital data to generate hydrographs that may then be routed using the SWMM5 dynamic wave method to determine flood depths which are subsequently mapped and exported for damage analysis on infrastructure systems. The simulation framework was used to simulate flows resulting from a dam break scenario. The SWMM5 engine performed capably as a flood routing model based on flow routing continuity error. The model also showed increased accuracy with decreasing computational time step. Future work will include an assessment of the models ability to conserve momentum for extreme flows resulting from dam break scenarios.

\section{Acknowledgments}

This research is funded by Los Alamos National Laboratory.

\section{References}

Crawford, N. H., and Linsley, Jr., R. K, (1966). Digital simulation in hydrology: Stanford Watershed Model IV, Tech. Rept. No. 39, Department of Civil Engineering, Stanford University, Stanford, California. 
Fread. D., (1991). The NWS DAMBRK Model: Theoretical Background/User Documentation. National Weather Service, NOAA, Silver Spring, Maryland.

Kalyanapu, A., Judi, D., Burian, S., Hodge, B., Berscheid, A., and McPherson, T. (2007). "Channel Morphology Tool (CMT): A GIS-Based Automated Extraction Model for Channel Geometry." Proceedings ASCE-EWRI World Environmental and Water Resources Congress, 15-19 May 2007, Tampa, FL.

Rossman, L., (2008). Storm Water Management Model User's Manual. US Environmental Protection Agency, Cincinnati, Ohio.

Singh, V. P., and Woolhiser, D. A. (2002). "Mathematical modeling of watershed hydrology." Journal of Hydrologic Engineering, 7(4), 270-292. 